\title{
MEASUREMENTS OF ICRF LOADING WITH A RIDGED WAVEGUIDE COUPLER ON PLT
}

\author{
G.J. Greene, J.R. Wilson, P.L. Colestock \\ C.M. Fortgang, ${ }^{\dagger}$ J.C. Hosea, D.Q. Hwang, ${ }^{2}$ and A. Nagy \\ Princeton Plasma Physics Laboratory \\ Princeion, New Jersey 08544
}

\begin{abstract}
An ICRF ridged waveguide coupler has been installed on PLT for measurements of plasma loading. The coupler was partialy filled with $\mathrm{TiO}_{2}$ dielectric in order to sufficiently lower the cutoff frequency and utilized a tapered ridge for improved matching. Vacuum field measurements indicated a single propagating mode in the coupler and emphasized the importance of considering the fringing fields at the wouth of the waveguide. Low power experiments were carried out at 72.6 and $95.0 \mathrm{MHz}$ without any external impedance matching network. Plasma loading increased rapidly as the face of the coupler approached the plasma, and, at fixed position, increased with line-averaged plasma density. At the lower frequency, the reflection coefficient exnibited a minimum ( $<8 \%$ ) at a particular coupler position. At both frequencies, measurements indicated efficient power coupling to the plasma. Magnetic probe signals showed evidence of dense eigenmodes suggesting excitation of the fast wave.
\end{abstract}

$t$ Present address: McDonnell Douglas Corp., Los Alamos, N.M.

* Present address: University of California at Davis

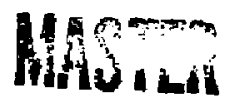




\section{INTRODUCTION}

[tilization of waves in the ion cyclotron range of frequencies (ICRF) has been shown io be an efficient means of heating thermonuclear plasmas [1]. Indeed, all of the present generation of large tokamaks (JET, JT-60, TFTR, T-15) will employ ICRF heating as one of several auxiliary sources of power. In its present design, the nextgeneration ignition device, CIT, will use ICRF heating as the sole source of non-ohmic power [2]. ICRF heating is particularly attractive because relatively economiral RF power generation is feasible in the frequency ranges appropriate for present tokamaks and future reactors. Efficient power transmission is also practical in this range of frequencies using simple coaxial line.

The above devices employ fundamentally similar antennas to launch the fast wave into the plasma. The couplers consist of one or more loops with RF current flow in the poloidal direction. The impedance presented by a loop coupler in the presence of plasma is, in general, different from the characteristic impedance of the transmission line which feeds it and hence some form of impedance matching is required to permit efficient power transfer to the plasma. Experimentally, the effective series resonant resistance of the loop antenna is small compared with the transmission line characteristic impedance, and peak voltzges on the antenna structure (which is generally a significant (raction of a wavelength in poloidal extent) can become high compared with voltages in the matched part of the line. In fact, breakdown at high-voltage points on the antensa or vacuum feedthrough imposes one limit on the RF power that can be applied to the antenna [3].

Conventional loop antennas also utilize Faraday shields over the current-carrying element. These shields serve to keep edge plasma from reaching the center conductor and to ensure proper polarization of the outgoing wave for coupling to the plasma. In practice, there is evidence that sputtering at the shield strips contributes to the detrimental increase in impurities seen during ICRF heating in some experiments [4].

There is considerable interest in the investigation of alternate ICRF couplers that. present potential advantages over conventional aniennas. Recent experimental efforts have cmployed several new designs. Very large area antennas were investigated on the Macrotor and CCT tokamaks [5]. Experiments with a parallel-plate transmission-line 
coupler were performed on JFT-2M $[6$. In addition, a wide loop antenna with a novel and complex center conductor (called a "fir-iree" antenna) is being studied in the T-10 tokamak [7].

It is natural to consider waveguide launchers in light of their successful use in other RF regimes (viz., lower hybrid current drive). Waveguide launchers are attractive because of their simplicity, possible lack of need for a Faraday shield, and potential cornpatibility with reactor scenarios where the heating antenna may need to be withdrawn following ignition. However, the appropriate cyciotron frequencies for present generation tokamaks are sufficiently low that a straightforward implementation with a rectangular waveguide would be impractically large.

A number of methods have been considered for reducing the transverse dimensions of a transmission structure necessary to carry a waveguide mode of a given frequency. Perkins [8] has investigated a re-entrant waveguide, and Owens [9] has discussed a folded or interdigital structure. A simple dielectric-loaded rectangular waveguide has been treated theoretically by several authois $[10,11]$. Another possibility, the ridged waveguide, was selected for the FED ICRF antenna conceptual design [12]. A ridged waveguide was also considered for the INTOR launcher concept [13], but it was noted that efficient coupling remajed to be demonstrated. Indeed, experimental verification of efficient. energy transfer to the plasma is of crucial importance for any proposed RF heating system.

This paper describes a coupler employing a dielectric-loaded ridged waveguide that was recently installed on the PLT tokamak in an orientation appropriate for fast wave excitation. Low power experiments were carried out to investigate the nature of the plasma coupling and its dependence on plasma parameters and antenna-plasma spacing. The experimental results reported here represent the first measurements of ICRF plasma coupling with a ridged waveguide. 


\section{RIDGED WAVEGUIDE ICRF COUPLER}

\subsection{Aidged waveguides}

The properties of a ridged rectangular waveguide were first discussed by Ramo and Whinnery [14] and by Cohn [15]. The lowest order propagating mode in such a waveguide is similar to the $\mathrm{TE}_{10}$ mode in a rectangular guide, although higher order modes ("trough" modes) exist which have no parailel in the rectangular system [16|. The primary advantage of a ridged waveguide for RF heating applications is the significantly reduced cutoff frequency of the lowest mode with respect to a rectangular waveguide of the same transverse dimensions. A decrease of $40 \%$ is easily achieved for a rectangular ridge of moderate proportions. In addition, the ridged guide has a wider bandwidth (separation between the first and second propagating modes) and lower characteristic impedance than a similar rectangular guide. These properties are a result of the increased capacitance between the ridge and the facing side of the guide. As a corollary, however, the power-handling capability is somewhat decreased due to the larger electric field in the gap region, and the attenuation per unit length is increased with respect to the corresponding guide without a ridge.

\subsection{Coupler design}

The port available for installation of a waveguide coupler on PLT had a width (in the toroidal direction) of $28 \mathrm{~cm}$. It was desircd to operate the coupler at frequencies below $100 \mathrm{MHz}$ in order to explore coupling in ICRF- relevant regimes and to permit event ual moderate power experiments with second-harmonic minority hydrogen damping. Given the geometric constraints, it was therefore necessary to load the waveguide with dielectric in order to lower sufficiently the cutoff frequency of the structure.

Two dielectrics considered for the waveguide were pure water $(\epsilon \approx 78$ ) and solid titanium dioxide ( $\epsilon \approx 85-95$ ). Water was ruled out because of the need for a robust window at the face of the waveguide and the potential for seriously compromising tokamak operations. Titanium dioxide was available in single pieces of a limited size $(2.54 \mathrm{~cm} \times 18.40 \mathrm{~cm} \times 25.40 \mathrm{~cm})$ so the guide was only partially filled with a block of the material (Fig. 1). Lack of dielectric in the two trough regions had little effect on 
the operation of the waveguide, however, because the electric field was concentrated in the gap region for the lowest propagating mode. A double-riclged waveguide with dielectric loading only in the gap region was investigated theoretically by Mager] [17], and, for the $\mathrm{TE}_{10}$ mode, the difference in cutoff frequency between that guide and one uniformly loaded with the same dielectric was found to be small $(<5 \%$ ).

The length of the wayeguide was also determined by practical constraints. It was necessary to make the guide a significant fraction of a wavelength long in order to prevent evanescent fields produced at the coupling probe from reaching the plasma. To avoid the technical difficulty of making a vacuum seal on the guide itself, and to avoid the need to abut blocks of the dielectric (which could lead to electrical breakdown due to the high electric field in the very thin vacuum gap), the guide was made the length of a single solid $\mathrm{TiO}_{2}$ block $(25.4 \mathrm{~cm})$. The distance between the top of the ridge and the facing side of the guide (i.e., the height of the "gap" region) was equal to the thickness of the dielectric block $(2.54 \mathrm{~cm})$, and the overall height of the guide was chosen to be three times the thickness of the dielectric.

The body of the ridged waveguide was made from copper plates $12.7 \mathrm{~mm}$ thick, and the back end of the guide was shorted with another plate. As it was important to provide good contact between adjoining plates and to prevent gaps between the conducting surfaces and the dielectric block, the individual copper pieces were lapped and the mating surfaces were silver plated. The surface of the $\mathrm{TiO}_{2}$ slab was ground and was plated with silver over the areas where it adjoined copper.

Coupling to the waveguide was accomplished with a probe, $3.2 \mathrm{~mm}$ in diameter, that passed all the way through the dielectric and made electrical contact with the top of the ridge. To prevent vacuum gaps, the pin was soldered into a silver-plated hole in the dielectric. The pin was located $10 \mathrm{~cm}$ from the shorted end of the guide and was centered above the ridge. The probe was fed from a $50 \Omega$ rigid copper coaxial transmission line which made an immediate 90 -degree bend and led to a $50 \Omega$ vacuum feedthrough bushing. A photograph of the completed ridged waveguide assembly mounted on the PLT vacuum flange is shown in Fig. 2.

The characteristic impedance of the generator and coaxial lines leading to the coupler was $50 \mathrm{\Omega}$; the real part of the surface impedance of the plasma was expected 
to be somewhat less, the value depending on the exact density profile in front of the waveguide mouth $[18\rfloor$. The width of the ridge of the waveguide was tapered in an attempt to improve the impedance match within the guide itself. The profile of the taper, the local cutoff frequency, and the local characteristic impedance for two frequencies of uperation are shown in Fig. 3 as a function cf axial distance along the guide for the structure described here (for these calculations, we have assumed uniform dielectric loading and use the expressions of Hoefer [19]). The local cutoff frequency varies from $52-58 \mathrm{MHz}$, and the characteristic impedance changes by a factor of 1.6 or 1.8 over the length of the guide, depending on the frequency. Note that the cutofi frequency for a rectangular waveguide of the same outside dimensions, completely loaded with $\mathrm{TiO}_{2}$ dielectric, would be $\sim 86 \mathrm{MHz}$.

\subsection{Vacuum field measurements}

Measurements of the vacuum fields produced by the open-ended waveguide were made using a miniature (2 mm o. ${ }^{\prime}$ ), 3-axis, electrostatically shielded magnetic probe. The magnitude of the signal from a probe coil measuring $B_{x}$ in front of the waveguide (where $x$ corresponds to the toroidal direction when the coupler is installed in the tokamak) is shown as a function of frequency in Fig. 4 (a). Peaks in the amplitude of the feld are seen at frequencies of $72.6,127$, and $187 \mathrm{MHz}$ ( $\mathrm{c}$ 'siresponding to frequencies at which the axial extent of the guide is approximately equal to a half-integral rumber of wavelengths). Correspondingly, minima or dips in the reflection coeffieient looking into the coupling probe are seen at these frequencies. Simulating a plasma load by placing a sheet of a resistive material [20] in front of the waveguide mouth increased the magnitude of the djps [Fig. 4 (b)], indicating that power was, in fact, being transferred to the load.

The actuai nature of the load presented by the plasma was not known, however, and it could not be assumed a priori that a real impedance was the appropriate representation. Due to the complicated calibrations required to perform the impedance measurements, it was not practical to sweep the excitation frequency during plasma experiments. Two fixed frequencies of operation were chosen for comparison in the experiments: $72.6 \mathrm{MHz}$, representing the lowest frequency at which the wayeguide 
demonstrated good coupling to a resistive loarl, and $95.0 \mathrm{MHz}$, where the impedance transformation properties of the cuuples were significantly clifferent.

The magnitudes of the three components of the magnetic field alung an axial line inside the trough of the guide are shown in Fig. 5. The fields are shown for the two frequencies of operation, and a node is apparent in the guide for the higher frequency case. The fields along two lines transverse to the guide and $2 \mathrm{~cm}$ in front of its face were also mapped out as shown in Fig. 6 for the $72.6 \mathrm{MHz}$ case. Apart from an overall scale factor, no discemible difference was found in the field structure measured outside the guide at the two different frequencies. This result confirms that the device was, in fact, propagating a single waveguide mote at least up to the higher frequency.

The forms of $B_{z}$ and $B_{x}$ represent field lines which loop out of sne side of the guide and into the other in a fashion similar to the expected result for a $\mathrm{TE}_{10}$ made in a rectangular guide. Note that $B_{y}$ becomes significani in front of the dielectric slab; this represents the effect of the ridge. The fringing fields near the edges of the guide (indicated by the peaks in $B_{x}$ at $x \simeq \pm w / 2$ ) are also appreciable and result from surface currents that flow on the outside of the structure. The phases of the $B_{x}$ fields in the two side-lobes are equal and differ by 180 degrees from the phase of the fieid in the central lobe. It is evident that the fringing fields are of significant magnitude and should be consirlered in any subsequent theoretical treatment; their effect, to first order, is to reduce the $k_{x}=0$ component of the wave Fourier spectrum.

\section{EXPERIMENTAL ARRANGEMENT}

The ridged waveguide was installed in PLT in a port of square cross section at the outer midplane of the vessel. The toroidal lacation of the coupler with respect to the limiters and other internal structures is shewn in Fig. 7. The coupler was adjacent on one side is the rotating limiter (positioned at minor radius $r=41.0 \mathrm{~cm}$ ) and on the other side to the fast-wave curr ${ }^{\circ}$ nt drive coupler side-limiters (located at $r=43.0 \mathrm{~cm}$ ). The ridged wareguide port was equipped with bellows permitting radial movement of the naveguide. In operation, the waveguide face was not positioned closer to the plasma than a: $r=43 \mathrm{~cm}$ in order to prevent damage to or coating of the dielectric 
by the plasma.

A low-loss adjustable line-stretcher connected the air-side of the vacuum feedthrough to a current-voltage ( $\mathrm{I}-\mathrm{V}$ ) coupler. This coupler is a transmission line device that provides RF signals proportional to the RF current $(I)$ and voltage $(V)$ at a point on the ine. Phase information is preserved, permitting analysis of the complex inpedanre at that point on the line. From this measurement, both the refiection coefficient and the squivalent series (or parallel) resonant resistance can be derived. When loading by the plasma is small, accuracy of the measurement can be increased by positioning the coupler at a location in the transmission line that maximizes the phase shjft between the current and voltage seen when the plasma is present, i.e., near a high-voltage or high-curreni point. The adjustable line stretcher was used for this purpose.

RF signals from the I-V coupler were conveyed to the control room via wideband analog fiber optic links. The signals were processed there with phase and amplitude detectors and were digitized at a $2 \mathrm{kHz}$ sampling rats. Adjustable step attenuators were used to equalize the signal levels to the extent required by the funite dynamic range of the phase detector. Phase accuracy was quite important for these measurements, and the entire system, including the optical links, was calibrated for each setting of the attenuators to an accuracy of less than one degree.

Two magnetic probes were located on the bottom of the vessel as shown in Fig. 7. One was directly beneath the ridged waveguide coupler and the other was located 120 degrees toroidally away. These probes consisted of mall balanced loops ( $2 \mathrm{~cm}$ o.d.) that measured the toroidal component of the wave magnetic field; they were typically located at a minor radius of $r=48.0 \mathrm{~cm}$ and thus sampled fields where the plasma density was very low. Signals from the probes were also brought to amplitude and phase processing electronics and digitizers using analog fiber optic links.

A single Langmuir probe was used to investigate plasma parameter profiles in the edge region near the coupler. The moveable probe, protected with a boron nitride sheath, was located $4 \mathrm{~cm}$ beneath the ridged wareguide and was attached to the same backplate. The exposed probe tip was a tungsten wire $1 \mathrm{~mm}$ in diameter and $4 \mathrm{~mm}$ long. In operation, the probe voltage was swept $\varepsilon:$ a rate of $60 \mathrm{~Hz}$, and the current and 
voltage signals were digitized at rates of $25 \mathrm{kHz}$. The probe was generally withdrawn during RF coupling experiments.

\section{LOADING CALCULATIONS}

Analysis of data from the $I-V$ coupler yields the complex impedance $Z=V / I$ at that point in the transmission line. In principle, if the complete transformation properties of the waveguide were known, the measured complex impedance could be related to the wave impedance at the waveguide mouth; in practice, this characterization is not currently feasible. Experimental measurements can be used to calculate two quantities which are indicative of the waveguide loading: the complex reflection coefficient $\left[\rho=\left(Z-Z_{0}\right) /\left(Z+Z_{0}\right)\right.$, where $Z_{0}$ is the characteristic impedance of the transmission line between the $1-V$ coupler and the waveguide] and the equivalent resonant resistance $\left(R_{*}\right)$. The latter is also referred to as a coupling resistance [21]. In a uniform transmission line connected to a passive load (the waveguide), there are two points in every half-wavelength of distance at which the impedance becomes purely real: the series and parallel resonances. The impedance at these points is given by $(1-|\rho|) /(1+|\rho|)$ and $(1+|\rho|) /(1-|\rho|)$. We define the coupling or loading resistance, $R_{p}$, as the real impedance which would be obtaired if the measured complex impedance were transformed along a uniform line in the direction of the antenna by a distance equal to the electrical length from the I-V coupler to the position of the resonance that occurs near the mouth of the waveguide. This definition is the same as the usual interpretation of equivalent resonant loading except that it provides for the rase $R_{s}>50 \Omega$, which is, in fact, observed. It will be seen below that the physical position of the resonance does not change significantly in the presence of plasma (except for the degenerate case $R_{1}=Z_{0}$ ). Note also that when the coupling is very small, $R$, provides a more useful indication of the loading than does $\rho$.

The efficiency of power transfer to the plasma, $\eta$, is of considerable importance. This efficiency is defined here as the ratio of the power coupled to the plasma to the total power dissipated on the load side of the I-V coupler, but in practice this quantity cannot be directly determined. If the loading by the plasma is small, then the 
current distribution in the waveguide coupler and transmission line does not change significantly in the presence of the plasma. In this case, intemal losses due to finite conductivity of the waveguide walls, djelectric losses in the $\mathrm{TiO}_{2}$, etc., can he arcounted for by an equivalent background or vacuum resonant resistance $R_{0}$, and the efficiency of power transfer is given by $\eta=\left(R_{3}-R_{0}\right) / R_{3}$. (This case ordinarily applies to conventional lcop ICRF antennas where the inductive reactance of the loop is significantly greater than the resistance in the presence of plasma.). Frr the case of heavy loading, however, the current distribution in the waveguide and transmission line can change, even if the position of the resonance does not. Simple models indicale that as long as the losses in the waveguide and transmission line arz small and relatively uniform in distribution, then, for the parameters appropriate to these experiments, $\eta$ remains a good estimate of the power transfer efficiency.

\section{EXPERIMENTAL RESULTS AND DISCUSSION i}

Experiments were performed in deuterium discharges with plasma line-averaged electron densities of $1-3 \times 10^{13} \mathrm{~cm}^{-3}$, plasma currents of $400-550 \mathrm{kA}$, toroidal magnetic fields of $26-32 \mathrm{kG}$, and RF powers of $0.01-5.0 \mathrm{~W}$. Typical central electron and ion temperatures were 1000 and $800 \mathrm{eV}$, respectively, and no auxiljary heating was employed. The raw signals from the $1-V$ coupler generally exhibited significant fluctuations $(10-20 \%)$ which were thought to be related either to density perturbations in the edge plasma or to eigenmode excitation. Computed values of $R_{\text {, were averaged }}$ over a 100 msec window (from 450 to 550 msec after the start of the discharge) during which the line-averaged density and other plasma parameters were approximately constant. In general, the loading measurements wers quite reproducible. The data set for which the impedance was analyzed comprised approximately one hundred tokamak discharges.

The variation of $R$, with the position of the face of the waveguide is shown in Fig. 8 for the two frequencies investigated. For these data, the line-averaged density was $\bar{n}_{e} \approx 1.4 \times 10^{13} \mathrm{~cm}^{-3}$, the plasma current was $45 \mathrm{G} \mathrm{kA}$, and the toroidal magnetic field at the tokamak axis $(r=0)$ was $B_{t}=31.3 \mathrm{kG}$. Each point shown on the plot 
represents the ruverage of results from 3-5 trkamak discharges. For botin the high and low frequency cases, the loriting rasistanire increases monctonically as the coupler approacies the plasma, while the background (acuim) loading remains nearly constant. Fo: the lata at $72.6 \mathrm{MIz}$. the background loading is approximately $10 \Omega$, white the lcading with plasma increases from a thinimum of $\sim 20 \Omega$ to a maximum of $\sim 75 \Omega$ as the coupier face nuves from $r=47 \mathrm{~cm}$ ii) $r=4.5 \mathrm{~cm}$. For the data at $95 \mathrm{MHz}$, the background loading is on the order of $0.2-C .4 \Omega$, and the loading in the presence of plasma increases frorn $\sim 0.6 \Omega$ to $\sim 2.6 \Omega$ as the coupler is irserted.

The functional form of the loading resistance is very similar for both cases, but the magnitude of the loading dffers by a large factor $(\sim 30)$. The vacuum loading $R_{c}$ also differs by approximately the same factor. The function $\eta$ is thus nearly the same at the two different frequencies, ranging from 0.5 to 0.85 as the coupler moves radially inward.

For the high frequency case. the loading is sufficiently small that the current distribution in the transmission line is largely unaffected by the presence of plasma. Although the magnitude of the reflection cjefficient was nearly unity in this case, efficient high power coupling could be accomplished in principle using. for instance, a double-stub tuner for impedance matching the approach routinely used for conventional ICRF antennas).

For the low frequency case, the value of the loading is large and passes through $Z_{0}$ at a particular coupler position $(\mathrm{r} \approx 43.5-44.0 \mathrm{~cm}$ ) To clarify the nature of the loading, the complex reflection coefficient measured at the I-V coupler location is plotted for the various coupler positions in Fig. 9. Except for the point ai $r=47 \mathrm{~cm}$, the data fall on a relatively straight line which passes through the origin. These data imply that the position of the resonance does not change siznificantly over the range of parameters shown. The points can be modeled approximately as resulting from a real load impedance, terminating a uniform line, which increases monotonically as the coupler approaches the plasma.

Some fraction of the background loading, $R_{0}$, may not be due to internal losses in the guide and transmission line, but to radiation from the open mouth of the guide. In a bench test, the open face of the wavezuide was shorted with a tiglt-fitting conducting 
sheet, the guide was resonated at $72.6 \mathrm{MHz}$, and the series resistance was measured. A value of 1-2 $\Omega$ was found which was considerably smaller than the $10 \Omega$ value observed as the vacuum loading. While this measurement can be misleading if some very local high-loss region happens to exist within the coupler, it is suggestive that a large part of the background loading is not, in fact, attributable to internal losses. When installed in the tokamak, vacuum losses external to the waveguide can occur from damping on the walls or possibly from actual radiation (the vacuum vessel has a number of ports which can allow RF current to flow to the outside of the vessel and subsequently radiate into free space). Thus $\eta$ should be viewed as a lower bound on the waveguide power tiansier efficiency.

To emphasize the practical consequence of the large loading resistance observed for tie $72.6 \mathrm{MHz}$ case, the magritude of the reflection coefficient is plotted as a function of the coupler position in Fig. 10. The reflection has a minimum near $r \approx 43.5-$ $44.0 \mathrm{~cm}$, and the value at that minimum is less than $8 \%$. Pannelier and Adam [22] reported initial calculations of ICRF coupling to a plasma with a double-ridged waveguide. Although the waveguide and plasma parameters were different from the case investigated here, the coupler reflection coefficient was predicted to have a minimum for a particular coupler-plasma spacing, a conclusion qualitatively similar to the result of this experiment.

In another series of shots, the variation of plasma loading with line-averaged density was investigated at $72.6 \mathrm{MHz}$ with other parameters held constant $\left(B_{i}=31.4\right.$ $\mathrm{kG}, I_{\vec{\gamma}}=450 \mathrm{kA}$, coupler face at $r=43 \mathrm{~cm}$ ). The density was changed by adjusting the programming of the gas puff valve. The results are plotted in Fig. 11 and show that the loading resistance increases by a factor of nearly two as the density increases from 1.2 to $3.1 \times 10^{13} \mathrm{~cm}^{-3}$.

The plasma loading did not show any significant variation with plasma current over the range of $400-550 \mathrm{kA}$, and there was similarly no change as the toroidal field was varied from 25.8-32.5 kG. The latter observation is important because, for operation of the guide at $72.6 \mathrm{MHz}$, the second harmonic hydrogen resonance layer scanned across the waveguide mouth. Lack of a change in loading indicales that damping due to residual hydrogen at this layer was not significant. There was also no change observed 
in the loading as the incident power ievel was varied over the range of $0.01-5.0 \mathrm{~W}$, providing some evidence that electrostatic sheath effects were not contributing to the loading.

RF signals from the two magnetic probes were monitored during a series of experiments with an excitation frequency of $72.6 \mathrm{MHz}$ and $\bar{n}_{e} \approx 1.3 \times 10^{13} \mathrm{~cm}^{-3}$, $I_{p} \approx 500 \mathrm{kA}$, and $B_{t}=31.3 \mathrm{kG}$. The amplitude of the two signals and the relative phase between them is shown for a typical shot in Fig. 12. Note that the RF pulse begins at $t=-0.1 \mathrm{sec}$, and some vacuum transmission to the probe directly beneath the ridged waveguide is evident. The dense peaks observed are suggestive of toroidal eigenmode excitation which has been previously observed in PLT in regimes where wave damping was small [23]. The mean amplitudes of the signals from the two probes are comparable, and at various times during the shot the phase signal settles to a constant value, indicating a coherent wave propagating around the machine. This result emphasizes that although efficient power coupling to the plasma was observed in these experiments, the ultimate destination of that power (i.e., to the plasma, to the vacuum vessel wall, or to radiation outside the machine) was not determined.

In order to investigate the nature of the plasma in front of the waveguide, a Langmuir probe scan was performed in a discharge typuical of these experiments ( $\overline{\boldsymbol{n}}_{e}=1.3 \times$ $10^{13} \mathrm{~cm}^{-3}, I_{p}=500 \mathrm{kA}, B_{t}=31.3 \mathrm{kG}$ ). The waveguide face was positioned at $r=47$ $\mathrm{cm}$, ard the probe was moved in steps from $r=46 \mathrm{~cm}$ to $r=41.8 \mathrm{~cm}$. Analysis of the probe data [24] led to the results plotted in Fig. 13. Although the absolute value of the density from a probe measurement should not be interpreted literally, the results can accurately indicate relative changes. The density inferred from the probe signals shows a nearly linear fali over the range $r=41.8 \mathrm{~cm}$ to $r=43.8 \mathrm{~cm}$, and a slower rate of fall beyond that point. The temperature data show significant fluctuations but indicate a rise at the innermost probe locations.

\section{SUMMARY}

A ridged waveguide coupler has been developed as a prototype ICRF launcher for PLT. The waveguide was filled with $\mathrm{TiO}_{2}$ dielectric in the gap region and utilized a 
tapered ridge. The guide propagated only the lowest mode over the frequency range used, and vacuum field measurements demonstrated a large component of $B_{x}$ in front of the coupler. Fringing fields arising from currents flowing on the outer surface of the guide were significant and altered the $k_{x}$ spectrum produced.

In low power experiments on PLT, the dependence of plasma loading on coupler position, plasma density, and excitation frequency was investigated. At frequencies of both 72.6 and $95.0 \mathrm{MHz}$, the loadjng resistance increased rapidly as the face of the coupler moved into the edge plasma, and the finctional dependence for the two cases was nearly jdentical. In addition, the ratio of plasma to vacuum loading resistance was nearly the same for a given coupler location. The magnitude of the plasma and vacuutm loadin, however, was larger by a factor of approximately 30 for the lower frequency case. This factor is presumably due to the different impedance transformation properties of the waveguide at the two frequencies.

At both frequencies, the ratio of plasma to vacuum loading was large (yielding $\eta \approx 0.85$ ) when the coupler was fully inserted. Measurements made $v$ ith the face of the guide shorted suggested that some of the vacuum losding may have been due to damping inside the vacuum vessel or to radiatjon rather tiran to internal losses, and the efficiency of power coupling to the plasma may thus have been even larger.

A Langmuir probe scan revealed a monotonically increasing density profile in front of the coupler face. Moving the coupler into the vessel, which increased the observed loading resistance, therefore resulted in increasing plasma density at the waveguide face. In another experiment, the loading resistance was found to increase significantly with a rise in line-averaged plasma electron density. These observations are independent and not equivalent, however, because previous work in PLT has shown little correlation between line-averaged and edge plasma densities.

Magnetic probe signals showed eigenmode-like structure which did not vary significantly in amplitude around the machine. Dense eigenmodes would be expected in PLT at these frequencies and fields, particularly since there was no resonance layer providing strong damping in the machine. This result provided some evidence that the power was actually being coupled to the fast wave.

The most important conclusion of this work is the demonstration that a simple 
ridged waveguide structure can provide nearly reflection-free coupling in the ICRF to a tokamak plasma when the waveguide-plasma separation is adjusted appropriately. The frequency at which this situation is possible can be seiected by altering the length of the waveguide. The lack of necessity for an external impedance-matching system is a significant advantage over conventional ICRF launchers.

\section{ACKNOWLEDGMENT}

This work was performed under U.S. D.O.E. contract number DE-AC02-76-CHO3073. 


\section{REFERENCES}

[1] WILjON, J.R., in Proceedings of the Course and Workshop on Applications of RF Waves to Tokamak Plasmas, Varenna, Italy (1984) 146.

[2] IGNAT, D., COLESTOCK, P., BLACKFIELD, D., HAMMETT, G., KERBEL, G., et al., Bull. Am. Phys. Soc. 31 (1986) 1563.

[3] OWENS, T.L., BAITY, F.W., HOFFMAN, D.J., WHEALTGN, J.H., Fusion Technol. 8 (1985) 381.

[4] COLESTOCK, P.L., COHEN, S.A., HOSEA, J.C., HWANG, D.Q., GREENE. G.J., et al., J. Vac. Sci. Tech. A (USA) 3 (1985) 381.

[5] TAYLOR, R.J., Nucl. Fusion 25 (1985) 117j; TAYLOR, R.J., MAU, T.K., JAEGER, E.F., MORalES, G.J., AND LAI, K.F., Bull. Am. Phys. Soc. 31 (1986) 1518.

[6] ODAJIMA, K., MATSUMOTO, H., KIMURA, H., HOSHINO, K., KASAI, S., e: al., in Proc. 4th lnt. Symp. on Heating in Toroidal Plasmas, Rome (1984) 243.

[7] LONGINOV, A.Y., KOLOSENKO, E.I., MIROSHNICHENKO, G.A., NIZHNIK, G. YA., TSURIKOV, Y.A., et. al., in Proc. 13th Eur. Conf. on Cont. Fus. and Plasma Heating, Schlieresee (1986).

[8] PERKINS, F.W., in Proc. 4th Int. Symp. on Heating in Toroidal Plasmas, Rome (1984) I 136.

[9] OWENS, T.L., IEEE Trans. Plasma Sci. PS-13 (1986) 934.

[10] VARTANIAN, P.H., AYERS, W.P., HELGESSON, A.L., I.RE. Trans. Microwave Theory Tech. MTT-A (1958) 215.

[11] LAM, N.T., LEE, J.L., SCHARER, J., VERNON, R.J., IEEE Trens. Plasma Sci. PS-14 (1986) 271.

[12] FRElJE, S., in Proc. 9th Symp. on Enginering Problems of Fusion Research, Chicagu, vol. 1 (1981) 859.

[13] INTOR GROUP, Nucl. Fusion 25 (1985) 1791. 
[14] RAMO, S., WHINNERY, J.R., Fields and Waves in Modern Radio (Jotan Wiley and Sons, N.Y., 1944).

[15] COHN, S.B., Proc. I.R.E. 35 (1947) 783.

[16] MONTGOMERY, J.P., IEEE Trans. Microwave Theory Tech. MTT-19 (1971) 547.

[17] MAGERE, G., IEEE Trans. Microwave Theory Tech. MTT-26 (1976) 413.

[18] FORTGang, C.M., COLESTOCK, P.L., HWANG, D.Q., in Proc. of the Course and Workshop on Applications of RF Waves to Tokamak Plasmas, Varenna, Italy, vol. 1 (1985) 408 .

[19] HOEFER, W.J.R., BURTON, M.N., IEEE Trans. Microwave Theory Tech. MTT30 (1982) 2190.

[20] For example, Eccosorb, a sheet material with controlled surface resistivity manufactured by Emerson \& Cuming (Canton, MA).

[21) THEILHABER, K., JACQUINOT, J., Nucl. Fur:on 24 (1984) 541.

[22] BANNELIER, P., ADAM, J., in Heating in Toroidal Plasmas (Proc. 4th Int. Conf. Rome, 1984) Vol. 2, CEC, Brussels (1984) 1115.

[23] THOMPSON, H.R., Ph.D. Thesis, Princeton University (1984).

[24] BUDNY, R., J. Vac. Sci. Technol. 20 (1982) 1238. 


\section{FIGURE CAPTIONS}

FIG. 1. Diagram of the ridged waveguide coupler.

FIG. 2. The completed ridged waveguide coupler mounted on the PLT vacuum flange.

FIG. 3. (a) Profile of the tapered ridge half-width $(w / 2)$ along the length of the waveguide. (b) Variation of the local cutoff frequency along the waveguide. (c) Variation of the local characteristic impedance along the waveguide for frequencies $f=\mathbf{7 2 . 6}$, 95.0 $\mathrm{MHz}$.

FIG. 4. (a) Magnetic probe ( $\left.B_{x}\right)$ signal power as a function of frequency of excitation. The impedance of the signal source was $50 \Omega$, and the probe coil was located at $z=0.0 \mathrm{~cm}, y=2.5 \mathrm{~cm}, z=2.0 \mathrm{~cm}$. The signal has been normalized az a function of frequency to account for both the probe response and the incident power level. (b) Magnitude of the reflection coefficient looking into the waveguide coupling probe, as a function of frequency, for the open-ended waveguide (upper trace). The effect of a resistive sheet in front of the guide is also shown (lower trace).

FIG. 5. Components of the RF magnetic iteld amplitude (plotted on a linear scale) measured inside the ridged waveguide as a function of the coordinate $z$. The wavesuide length in the $z$-direction is denoted by $L$. The probe was scanned along the line $x=6.5 \mathrm{~cm}, y=2.6 \mathrm{~cm}$. (a) $f=72.6 \mathrm{MHz}$. (b) $f=95.0 \mathrm{MHz}$.

FIG. 6. Components of th: RF magnetic field amplitude (plotted on a linear scale) measured in front of the face of the ridged waveguide as a function of the coordinate $x$ (for $f=72.6 \mathrm{MHz}$ ). The waveguide widch in the $x$-direction is denoled by $w$. (a) Probe scan along the line $y=6.4 \mathrm{~cm}, z=2.0 \mathrm{~cm}$. (b) Probe scan along the bine $y=2.6 \mathrm{~cm}, z=2.0 \mathrm{~cm}$.

FIG. 7. Lacations of the ridged waveguide, plasma limiters, and magnetic probes in the PLT vacuum vessel.

FIG. 8. $R$, as a function of the position of the waveguide face. Open circles represent data taken during tokamak discharges; solid circles represent vacuum loading data. (a) $f=72.6 \mathrm{MHz}$. (b) $f=95.0 \mathrm{MHz}$. 
FIG. 9. Plot of the complex reflection coefficient, $\rho$, measured at the $\mathrm{I}-\mathrm{V}$ coupler location, as a function of the position of the waveguide face $(f=72.6 \mathrm{MHz})$. Here solid circles represent data taken during tokamak discharges; the open circle is the result for the case of vacuum loading when the waveguide face is at a minor radius of $43.0 \mathrm{~cm}$. The boundary $|\rho|=1$ has been drawn for reference.

FIG. 10. The magnitude of the reflection coefficient as a function of the position of the waveguide face for $f=72.6 \mathrm{MHz}$. The open circles represent plasma loading; the solid circles, vacuum loading.

FIG. 11. $R$, as a. function of the line-averaged plasma electron density ( $f=72.6 \mathrm{MHz}$ ). The waveguide face was at a minor radius of $43.0 \mathrm{~cm}$.

FIG. 12. Magnetic probes signals during a ridged waveguide experiment wich $f=72.6$ MHz. (a) Amplitude of the signal from probe 1. (b) Amplitude of the signal from probe 2. (c) Phase between the two probe signals.

FIG. 13. Results if the Langmuir probe scan adjacent to the ridged waveguide. (a) Electron density. (b) Electron temperature. 


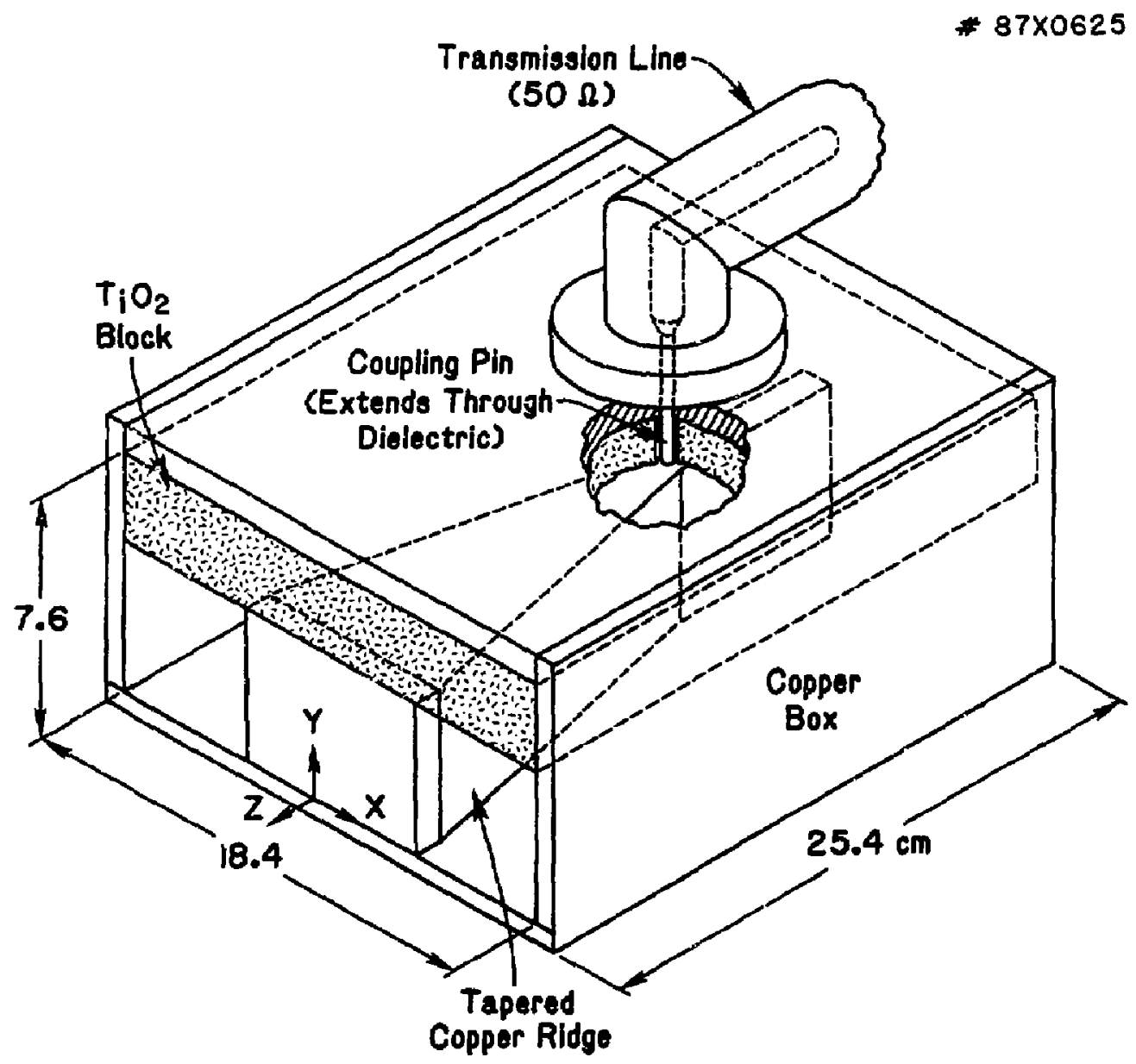

FIg. 1 


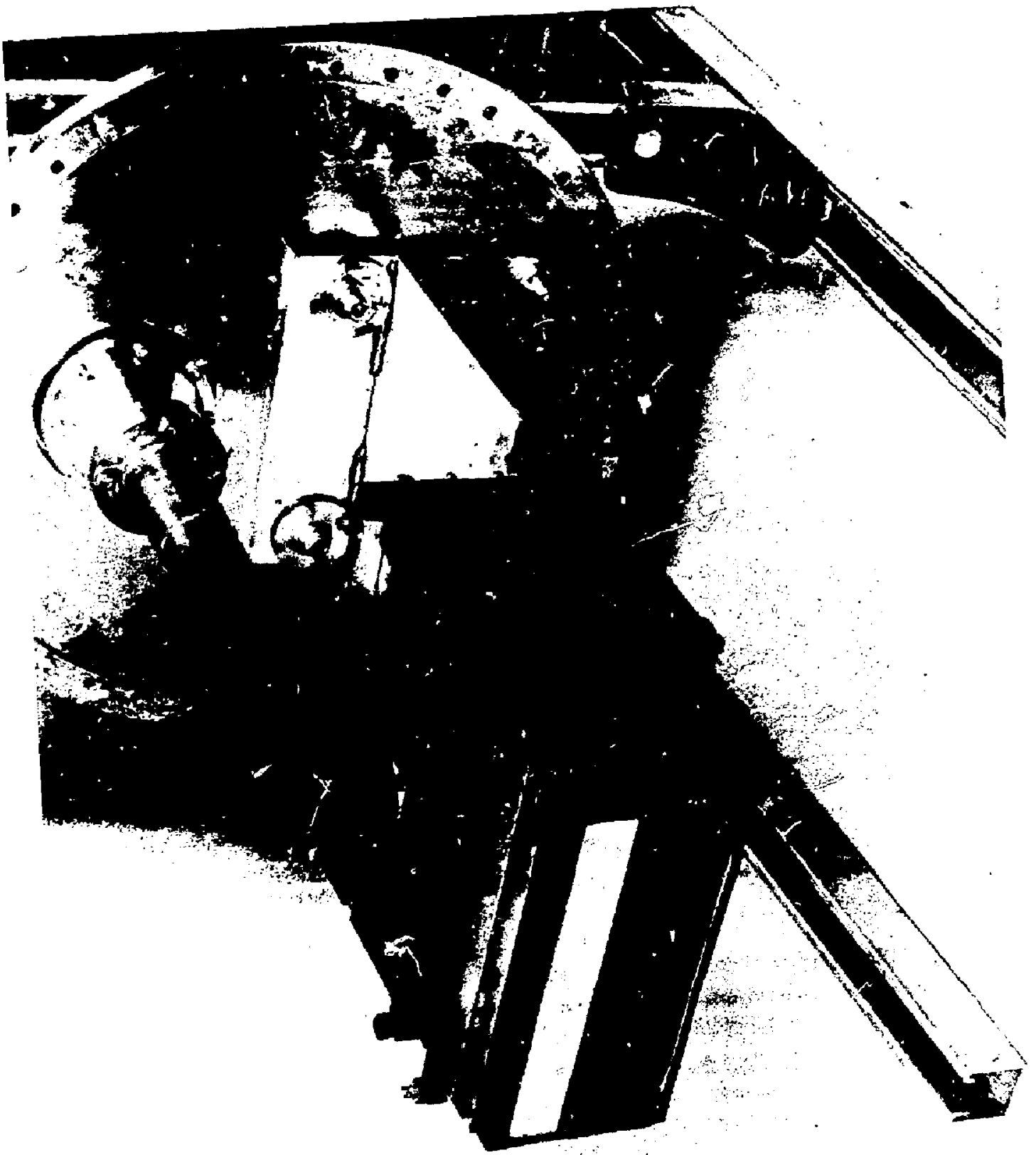




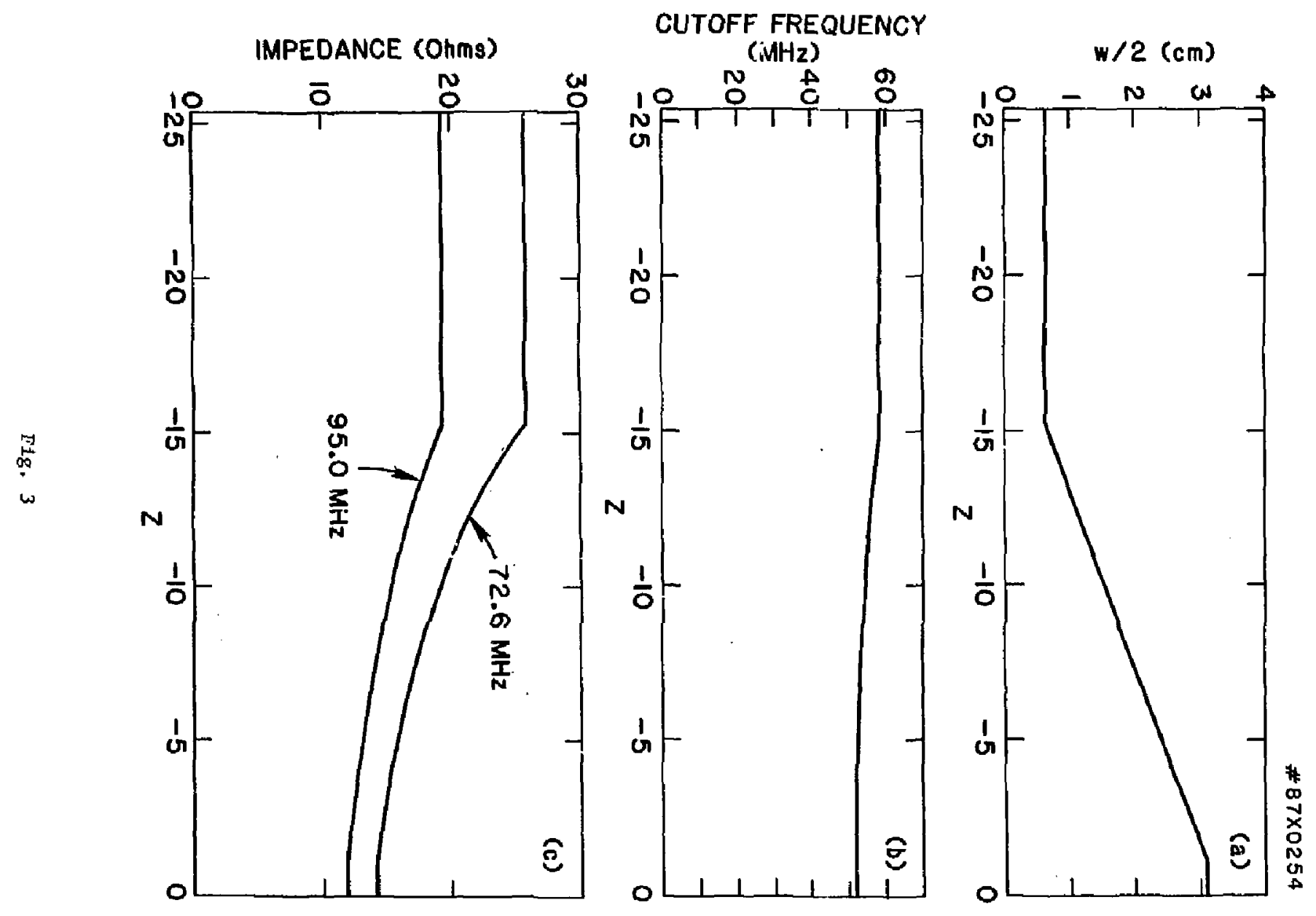



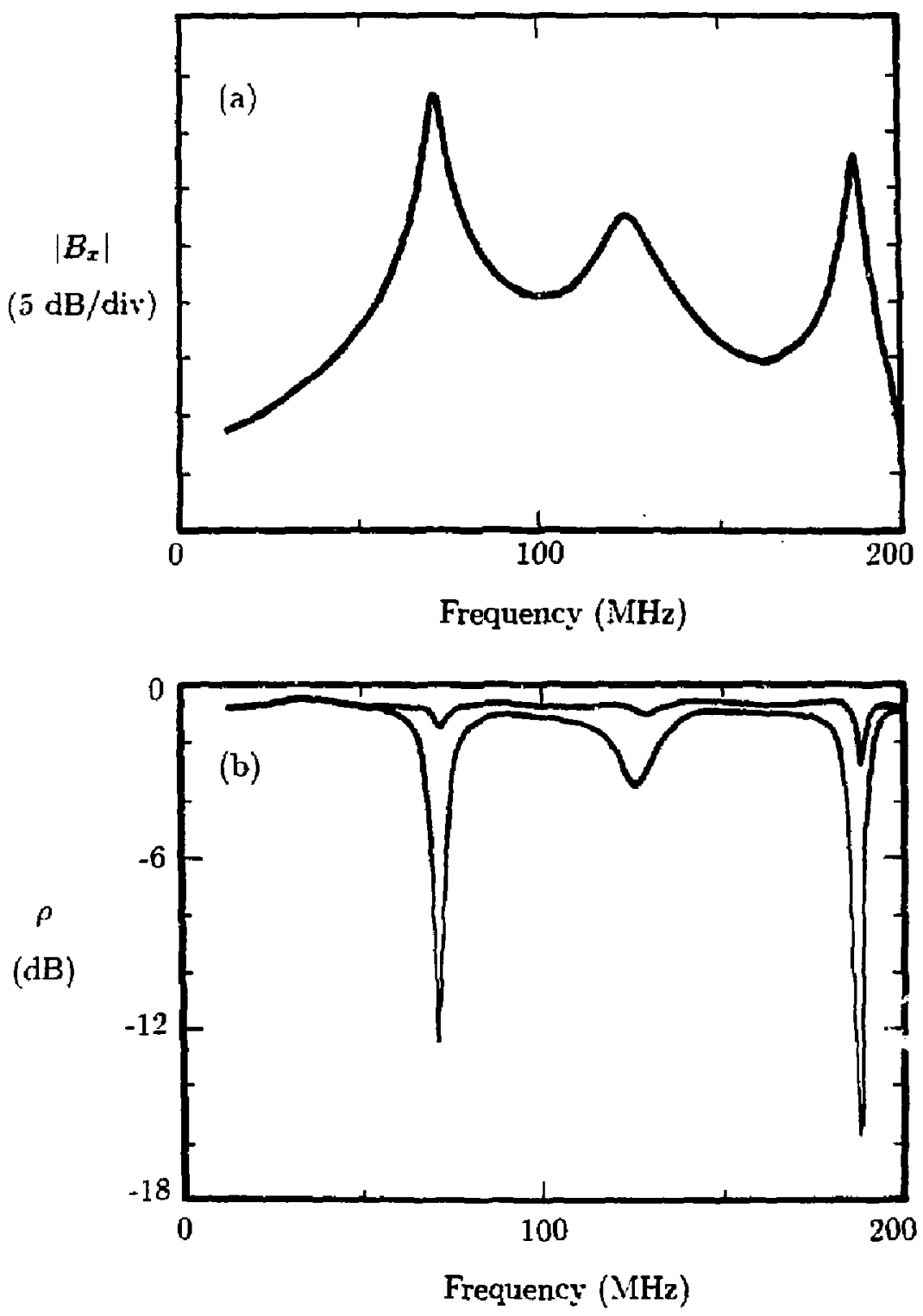

Fig. 4 
*87x0221

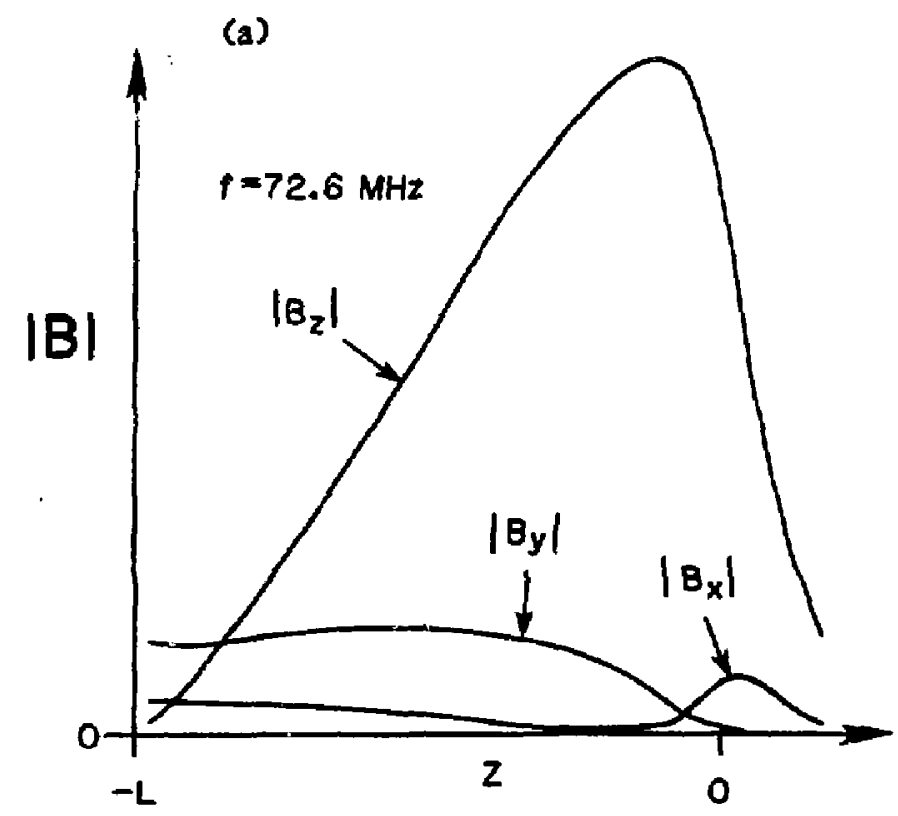

(b)

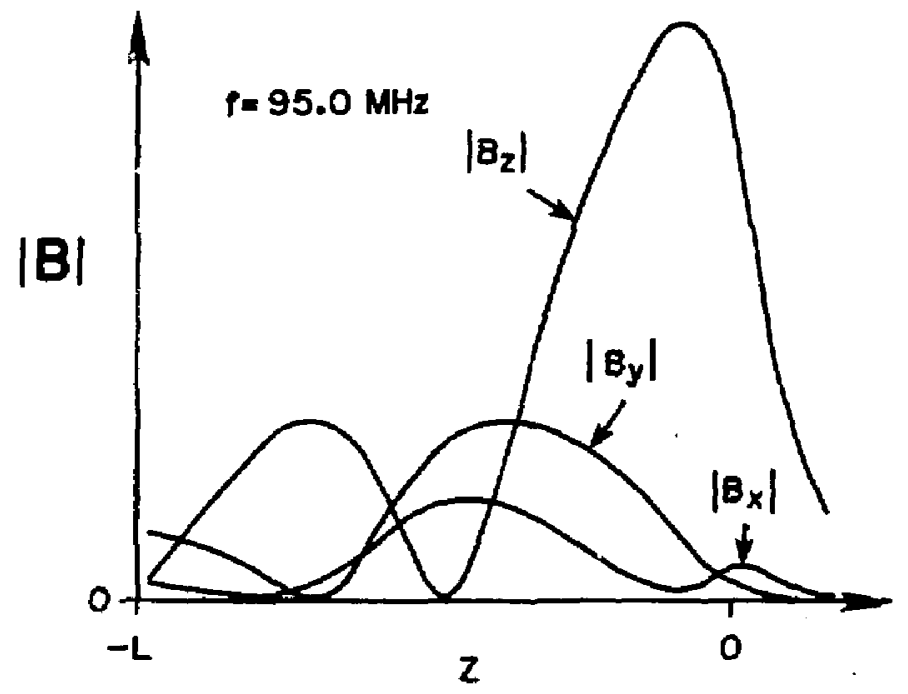

FIg. 5 
\#87x0220
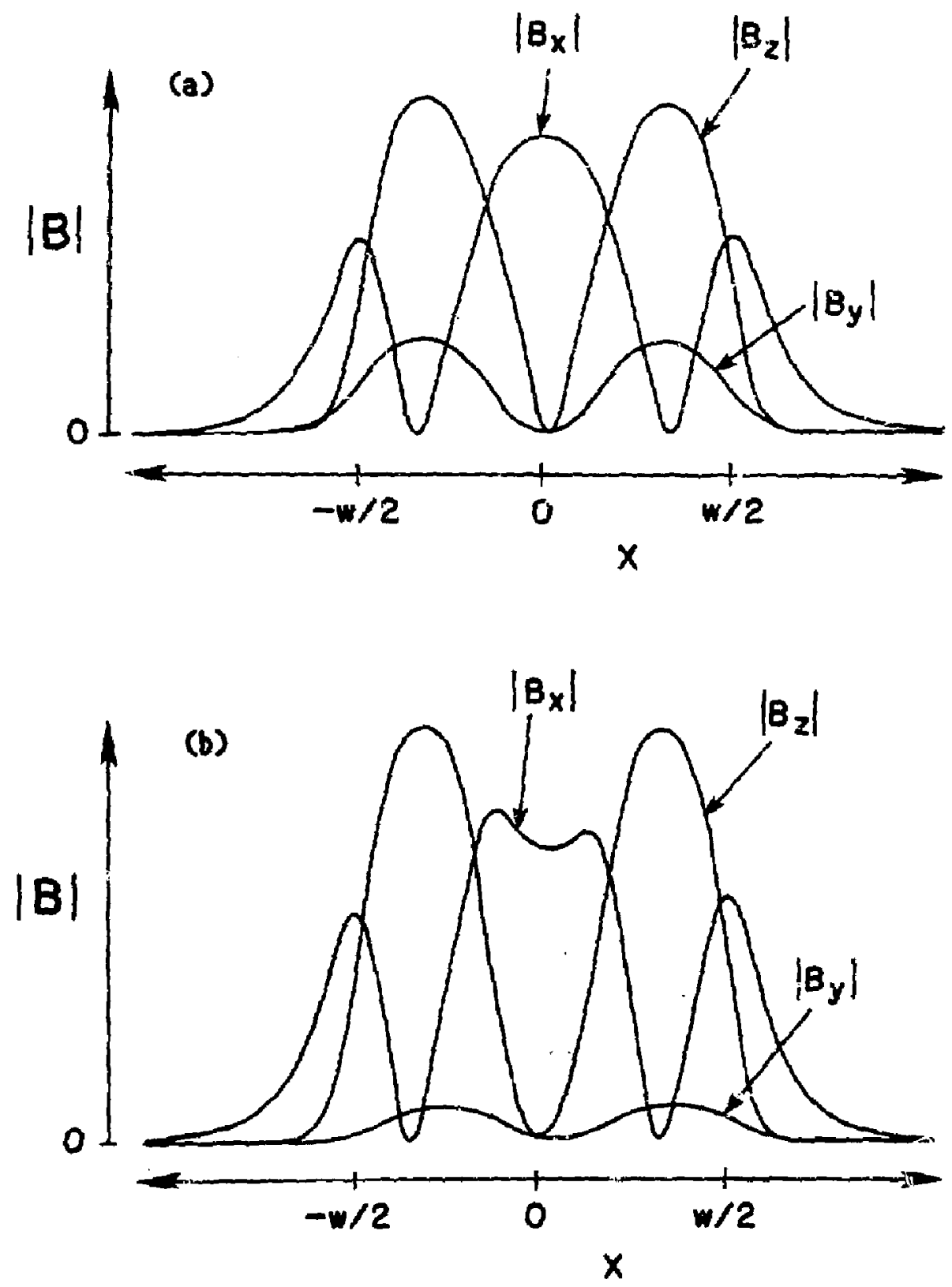

Fig. 6 


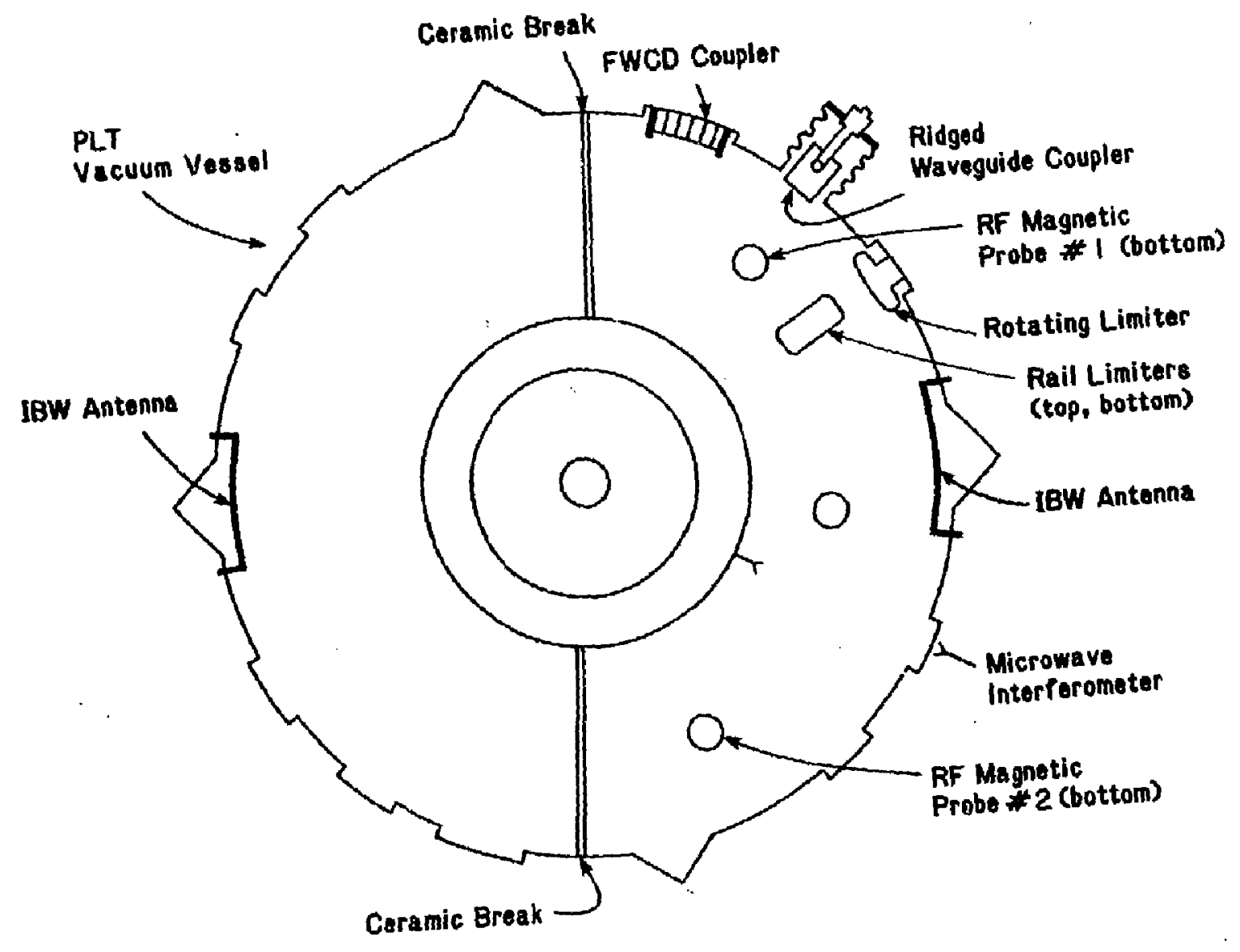

Fig. 7 

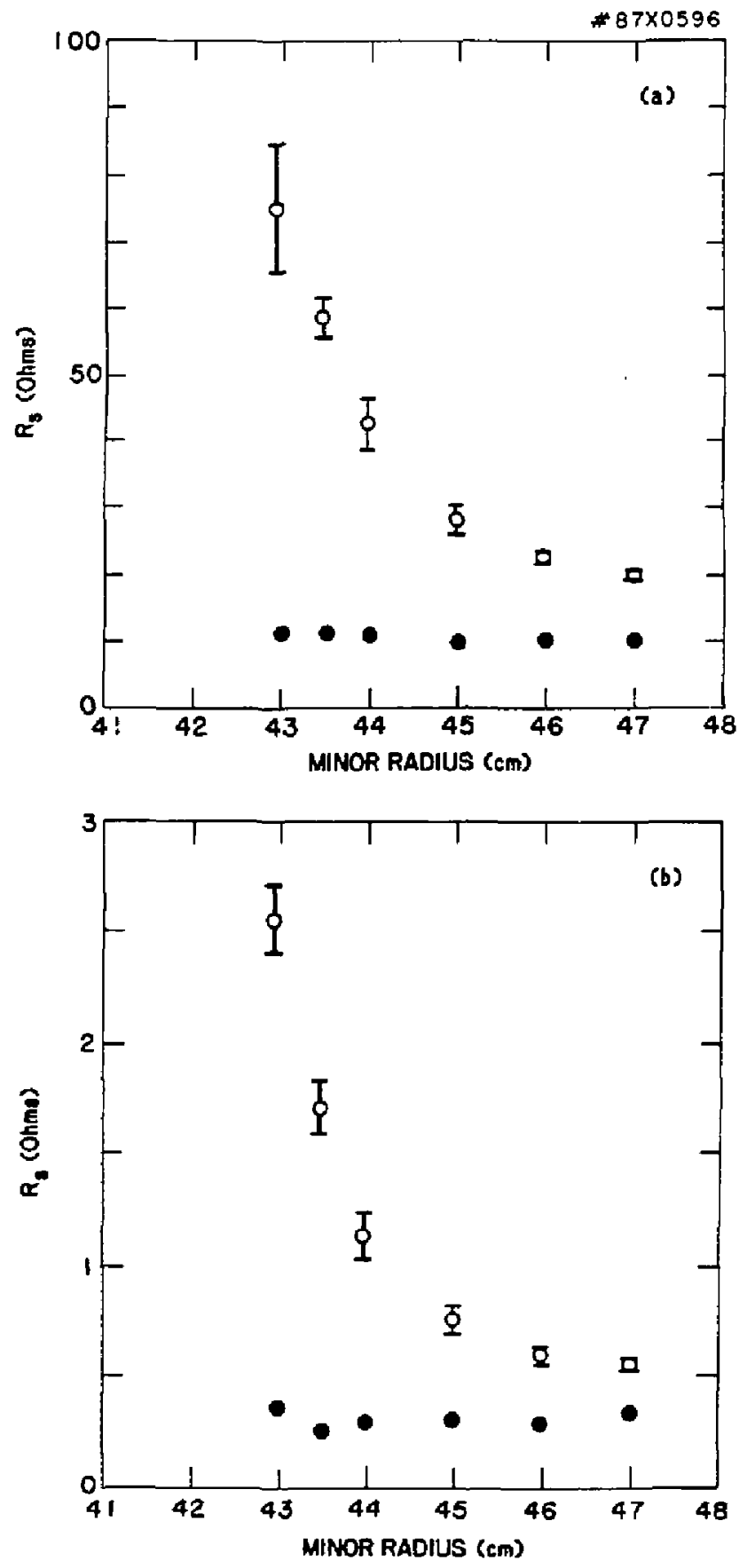

Fig. 3 


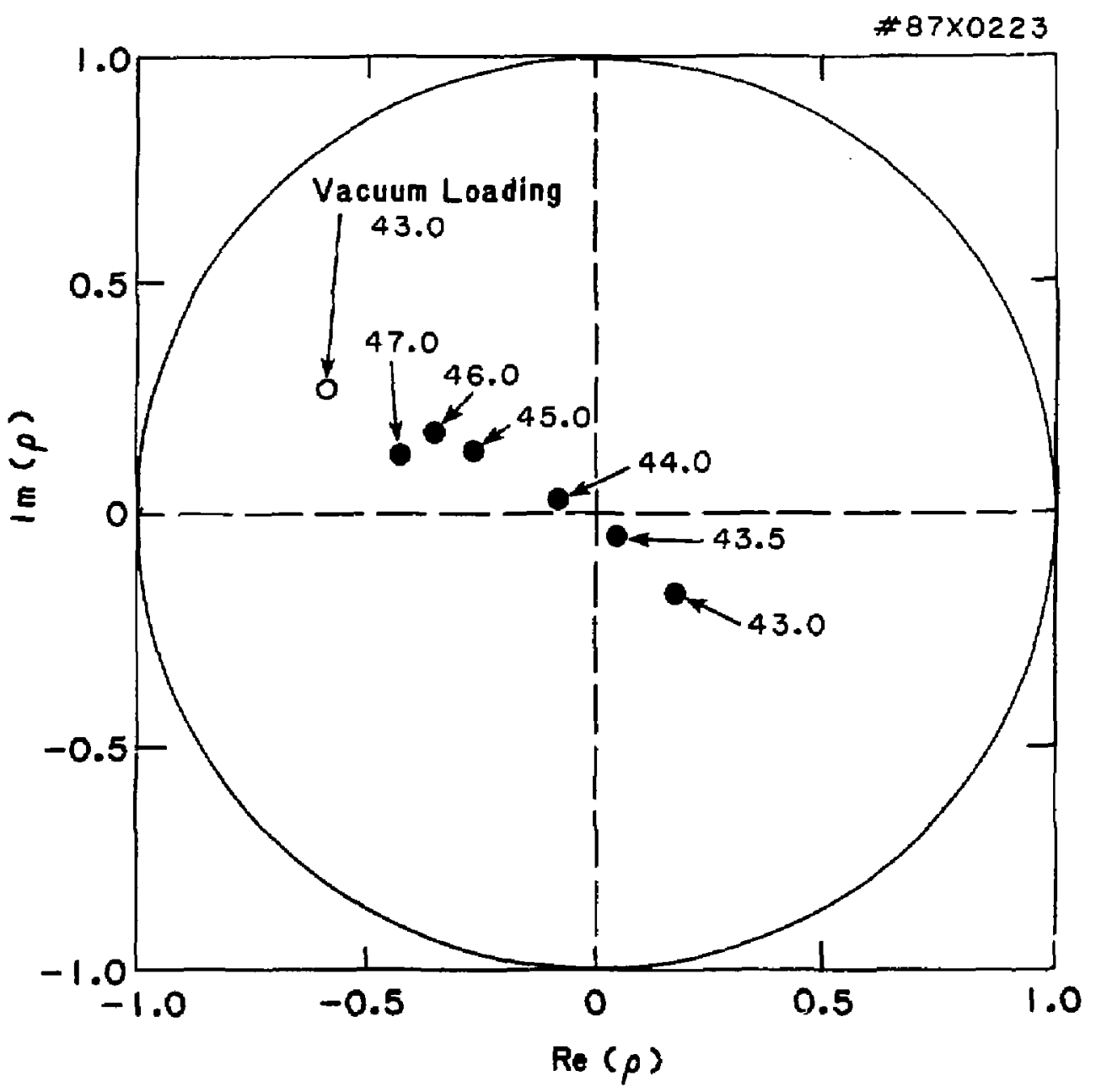

F1g. 9 


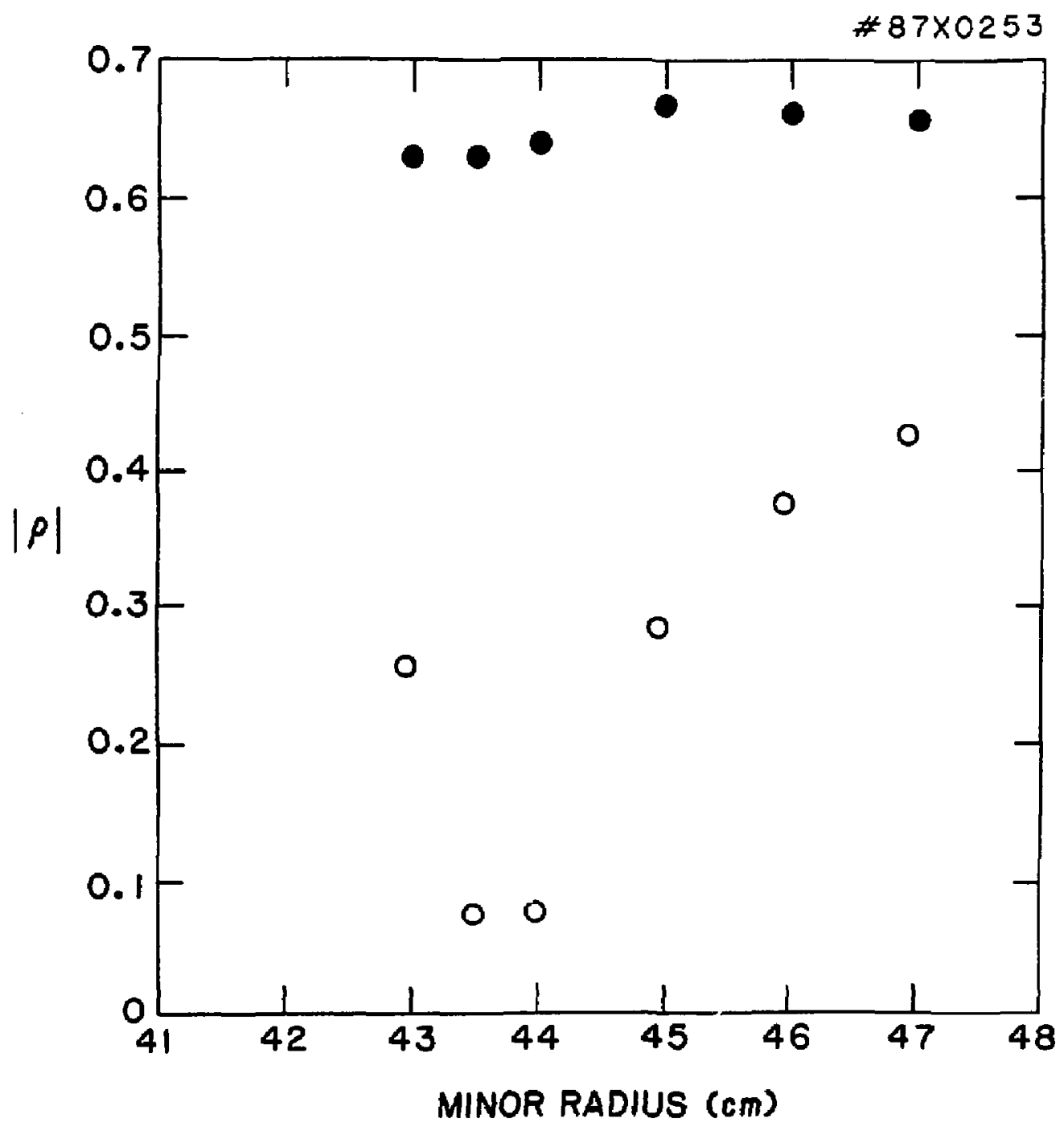

F1g. 10 
$-30-$

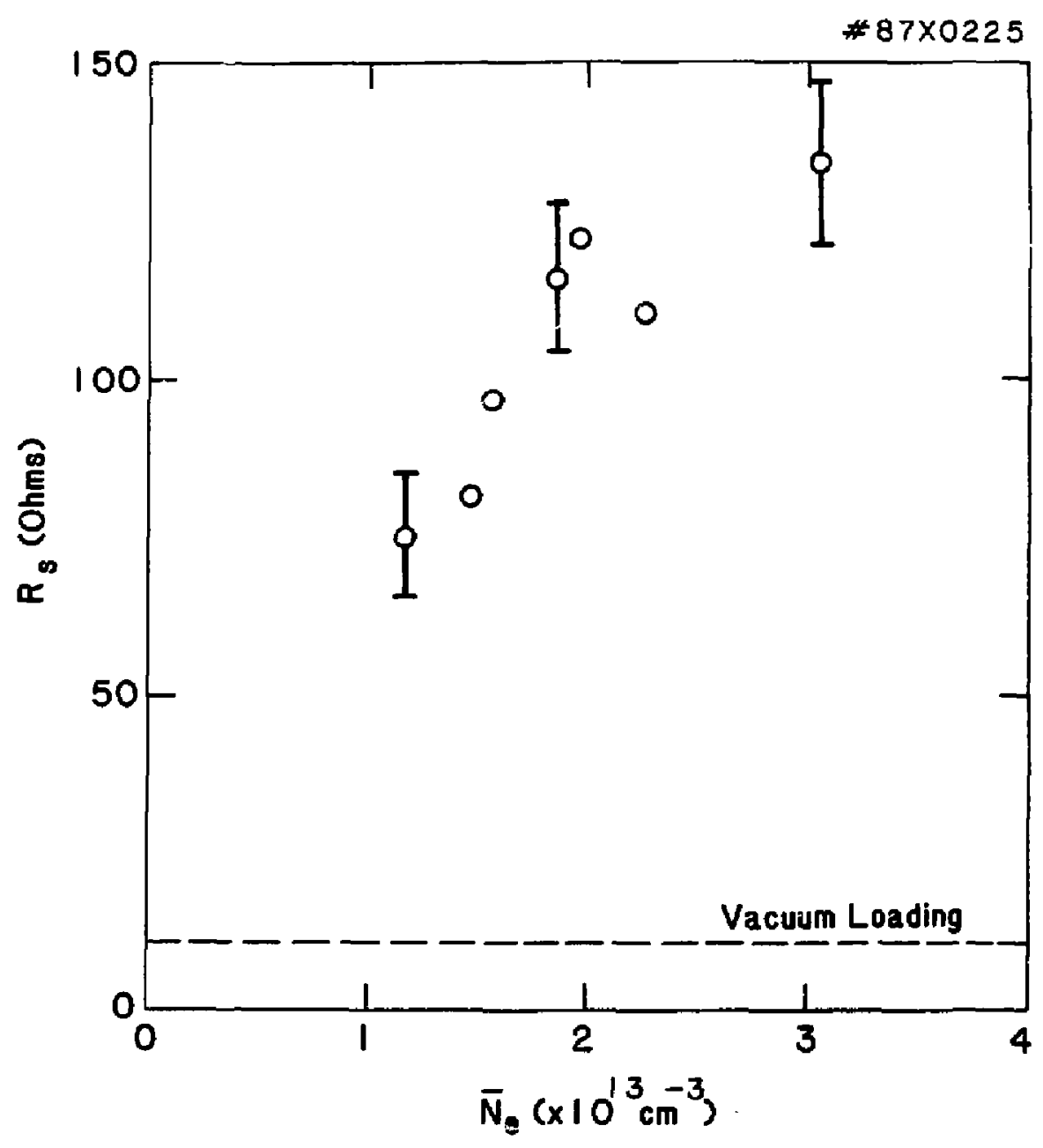

FIg. 11 


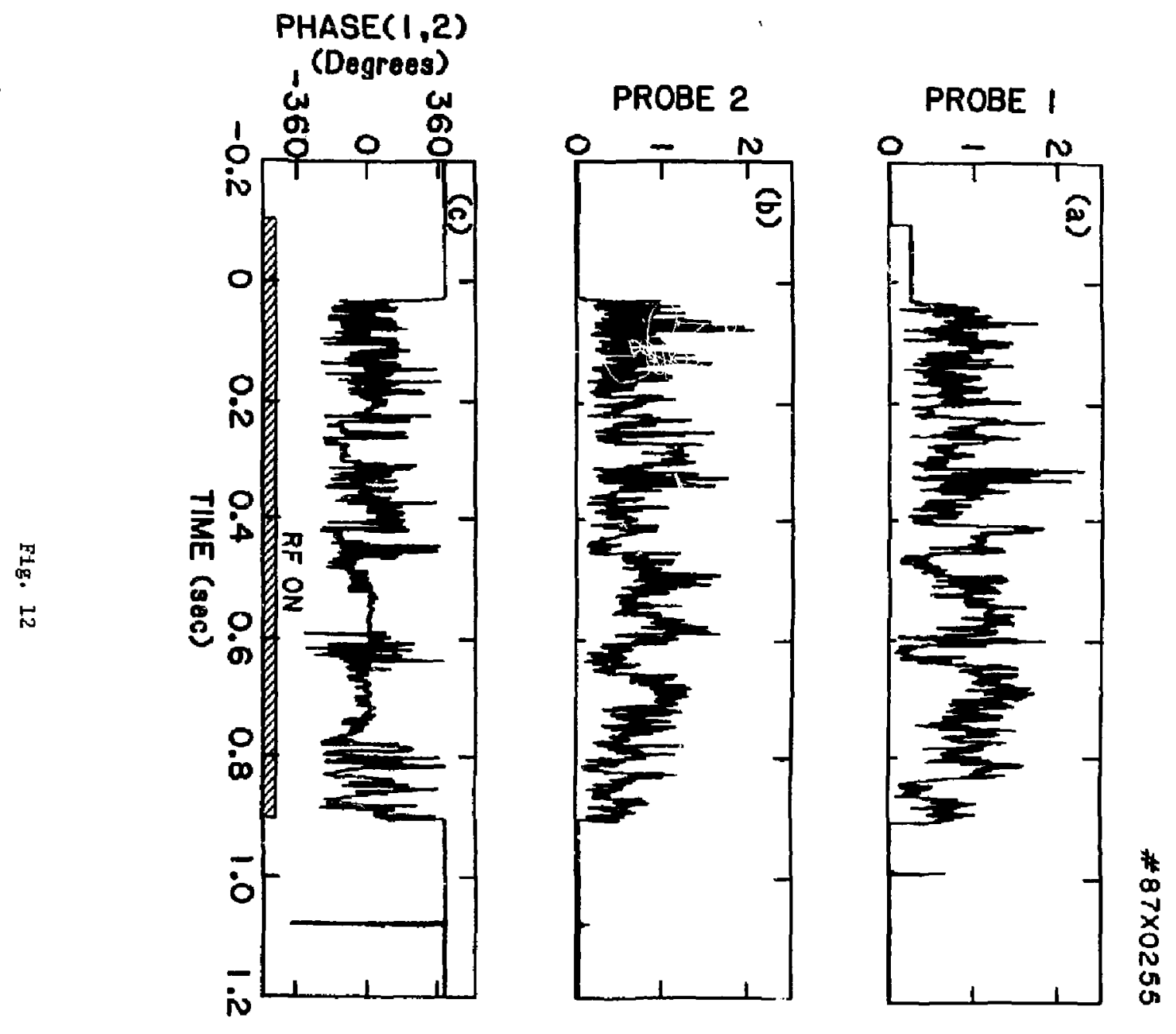



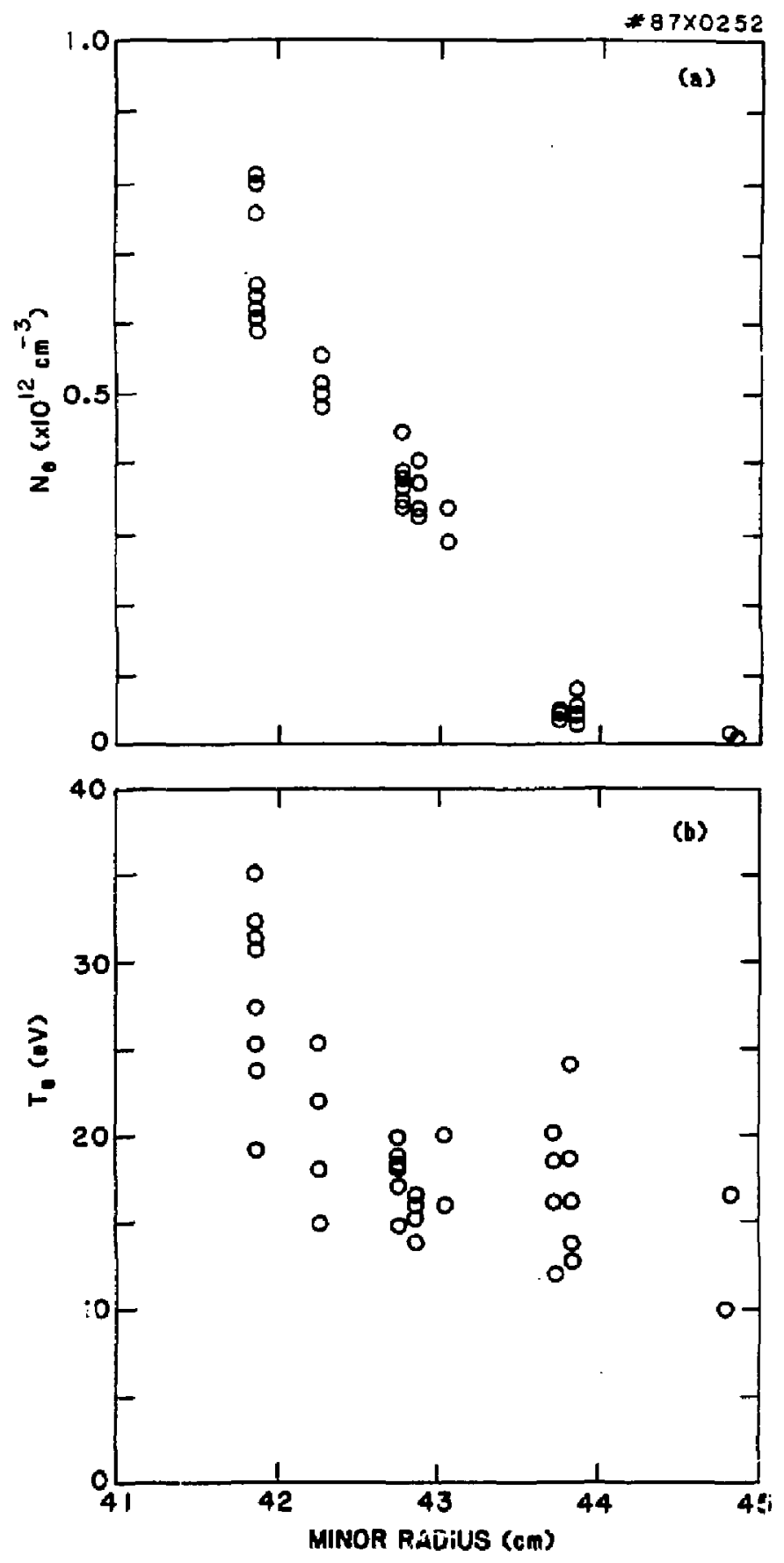

EIg. 13 
Dr, Frank J. Faalonl, Ualv of Wollongong, AJTRALIA

Prot, Ma, Brennan, Unir Sydney, NJTRALIA

Plasmo Reseorch Lab,, Austrslian Nat. UnIV , AUSTRALIA

Prot. I.R. Jongs, FI inders Unlv., MuSTRALIA

Prot. F. Cop, inst Theo Phys AUSTRIA

Prot. Ho Heindlar, Institut fur Thearetische Physik, AUSTRIA

M. Goossens, Astronamiseh Instituut, BELGILA

Ecole Royale Milltalre, Lab de Phys PIasnas, BELGIUH

Coni. of European, Dg Xil fusion Prog, Belgium

Prot, R, Bouclquie, Laboratorlim voar Notuurkunde, Belgilu

Dr. P.H. 5akenaka, Univ Estadual, RAZIL

Instituto Do Posquisas Especlas I-INPE, ERAZIL

Llbrary, Atomle Energy of Canade LInlited, CANADA

Dr. M.P. Bechynskl, MPG Tuchnologles, Inc, CANAOA

Or. H.M. Skarsgard, Univ af Saskatchewan, CANADA

Dr. H. Bernard, Unlversity of Britlsh Columbla, CNADA

Prot. J. Tolchmann, Univ, of Montrad, CANDA

Prot. 5.R. Sreanlvasan, Unluars Ity of Calgary, CANAOA

Prof. Tudor W. Johnston, IRPS-Energle, CNHADA

Or. C.R. James, UIIV of alburta, CANADA

Dr. Pote- Lukac, Komenskeho UnIv, CZECHOSLOVAKIA

The Llbrarlan, Culnem Laboratory, EMGLAND

Mrs. S.A. Hutehinson, JET LIbrary, EMGLMO

c. Mouttot, Lab. de Physlaue des Milleux lonises, FRACE

J. Rad t, CEN/CNOARACHE - Bat 506, RRAMCE

Or. Ton thol, Agadery Blbllographle. hons kOAG

Preprint Llbrary, Gene Res inst Phys, HUNGaRr

Dr. B. Desgupta, Saha Inst, IMOIA

or. $7, K$, Chhajlanl, VIkron Univ, INDIA

Or. P, Kow, Instituta for Plasena Research, INDIA

Dr. Phillip Rosenau, Isroel Inst Teeh, ISRAEL

Prot. S, Cuporman, Tal Aulv Untuarsity, ISRAEL

Librarian, Intrl ctr Theo Phys, ITALY

Prof. G. Rostagni, Uniy ol Padova, ITALY

Miss clel ra de Palo, Assoc EUAMTOM-ENEA, ITALY

BIbllotece, del COR EURATOH. ITNLY

Or. H. Yamito, Toshlbe Res \& Dev, INAN

Praf. 1. Kewakeal, Atonle Energy Ros, Institute, JAPAN

Prof. KyoJl NIshikewa, UnIV of HIroshimo, JAPAN

Direc, Dept. Lg. Tokenak Res. JAERI, JNPAY

Prot. Sotoshl Itoh, Kyushu UnIverslty, JAPAN

Resnoreh Into Canter, Nogoya UnIversity, JAPAN

Prot. S. Tanaka, Kyoto Unlversity. JAPNH

Library, Kyoto unlversity, JAPAN

Prot. Nobuyukl Inowe, unlvorsity of Tokyo, JAPNH

5. MOF 1, JAERI, JNPAN

MeH. KIn, Kores Advanced Enargy Resuarch Institute, KOREA

Prot, O.l. Chol, Adr, Inst Sel \& Tech, KOREA

Prof. B.S. LIley, Unlyarsity of Walkato, NEW 2EALAND

institute of Plasme Physlcs, PEOPLE'S REPUBLIC Of CHIHA

Librarlan, Inat1tut of Phys, PEOPLE'S REPULIC SF CHINA

LIbrary, Tslag Hus Unlversity, PEDPLE'S REPUBLIC Of CHIMA
Z. L1, Southwest Inst. Physies, PEOPLE'S REPULIC OF CHINA Prot. J.A.C. Cabral, Inst 5uparlor Teen, PORTUGAL

Dr. Octurlan Petrus, AL I CUZA UnIvarsity, ROMANIA Dr. Johan do Villiers, Plasmo Physics, AEC, 50 AFRICA Prot. M.A. Hellbarg, Universlty of Natal, SO AFRICA Fusion DIY. LIbrory, JEH, SPAIN

Or. Lennart Stenflo, Unlvorsity of IMEA, SWEOEN Llbrary, Royal inst Toch, SWEOEN

Prot. Hans Wlinelason, Chsimers Unit Toch, SWEDEN

Centre Phys des PIasmas, Ecolo Polytech Fed, SwITZERLAWD albil lotheak, Fom-l inst voor PIasmg-Fysice, THE NETHERLANDS Dr. D.D. Ryutav, SIberlan Acad SEl, USSR

Or. G.A. Ell seov, Kur chatov I nstitute, USSR

Or. V.A. Glukhlkh, Inst Electro-Physical, USSR

Dr. V.T. Tolok, Inst. Phys, Tech. USSR

Dr. L.M. Kovelizhnykh, Institute Gent. Fnysies, USSR Prof. T.J.H. Boyd, Univ Collego N Walos, WALES Nuclear Ros. Establishmont, Jul lich LTO., W. GERMANY Bibllothak, Inst, Fur Plasmoforschung. W. GERMWiY Dr. K. Schladiar, Ruhr Universitat, W, GERMANY ASOEX Rasdling Rm, IFPiMax-PIancei-Institut fur

Plasmaphysik, W. GEFMAKY

Llbrarlan, Wax-Planck Institut, W, Genuwy

Prot, R.K, Janov, inst Phys, YugosLAVIA 